\title{
MECANISMOS DE NITRETAÇÃO SOB PLASMA DO AÇO INOXIDÁVEL MARTENSÍTICO AISI 420 NITRETADO A ALTA E BAIXA TEMPERATURA
}

Carlos Eduardo Pinedo ' Rodrigo Magnabosco ${ }^{2}$

\section{Resumo}

Este trabalho apresenta o mecanismo de formação da camada nitretada sob plasma em baixa e alta temperatura para o aço inoxidável martensítico AISI 420, suas características morfológicas, cinéticas e de endurecimento. Na nitretação sob plasma a alta temperatura (HTPN) a termodinâmica desempenha o papel mais importante no mecanismo de nitretação e, neste caso, a elevada interação entre $\mathrm{Cr}-\mathrm{N}$ controla o crescimento caracterizado pela intensa precipitação de nitretos de cromo na zona de difusão. No entanto, na nitretação sob plasma a baixa temperatura (LTPN) a restrição cinética supera as necessidades termodinâmicas e o mecanismo de formação da camada nitretada é alterado, suprimindo a precipitação de nitretos de cromo e formando martensita revenida expandida $\left(\alpha_{N}^{\prime}\right)$ com a precipitação simultânea de nitretos de ferro. Os diferentes mecanismos operantes a alta e a baixa temperatura também modificam a capacidade e as características de endurecimento superficial, bem como a resistência à corrosão e a dureza original do substrato.

Palavras-chave: Nitretação sob plasma; Aço inoxidável martensítico; Martensita expandida; Endurecimento.

\section{ON THE MECHANISMS OF PLASMA NITRIDING OF MARTENSITIC STAINLESS STEEL AISI 420 AT LOW AND HIGH TEMPERATURE}

\begin{abstract}
In the present work a discussion on the nitriding mechanism as a function of temperature, as a balance between thermodynamic and kinetics aspects is presented. After High Temperature Plasma Nitriding (HTPN) thermodynamics plays the most important role on nitriding mechanism and high interaction characteristic between $\mathrm{Cr}-\mathrm{N}$ controls the case growth with intensive chromium nitrides precipitation. However, at Low Temperature Plasma Nitriding (LTPN) kinetics restriction overcomes thermodynamics needs and the nitrided case mechanism is changed, no chromium nitrides precipitation occurs and the nitrided case growths with expanded tempered martensite $\left(\alpha_{N}^{\prime}\right)$ formation and iron nitrides precipitation. These different nitriding mechanisms operating at low and high temperature modify the hardening effect, the corrosion resistance and the core hardness.
\end{abstract}

Keywords: Plasma nitriding; Martensitic stainless steel; Expanded martensite; Hardening.

\section{INTRODUÇÃO}

A nitretação é um tratamento termoquímico amplamente utilizado no tratamento de superfície de aços e de ligas. As principais vantagens do processo são o aumento da resistência ao desgaste, à corrosão e à fadiga [I]. A nitretação sob plasma é o processo mais atual e versátil em uso industrial. A possibilidade de controle da microestrutura da camada nitretada é a vantagem mais importante para a nitretação sob plasma sobre o processo de nitretação convencional líquida ou gasosa [2-4]. Este controle microestrutural é realizado com a seleção correta dos principais parâmetros do processo, tais como a composição da mistura gasosa, temperatura e tempo.

Aços inoxidáveis martensíticos são usados em uma ampla gama de aplicações como, por exemplo: gás e petróleo, talheres, aparelhos médicos e odontológicos, moldagem de plástico, entre outras. Para todas estas aplicações, o aumento na resistência ao desgaste é importante para melhorar o desempenho, mas a melhoria nesta propriedade não deve prejudicar a resistência à corrosão do material. Neste caso, o controle da microestrutura obtida no processo

\footnotetext{
'Heat Tech Tecnologia em Tratamento Térmico e Engenharia de Superficie Ltda, Mogi das Cruzes, SP, Brasil. E-mail: pinedo@heattech.com.br ${ }^{2}$ Departamento de Engenharia de Materiais, Centro Universitário da FEI, São Bernardo do Campo, SP, Brasil.
} 
de nitretação é uma questão essencial para aumentar o desempenho. É preciso considerar o alto teor de cromo no aço e sua influência sobre a estabilidade dos nitretos, uma vez que este elemento tem uma influência decisiva sobre a morfologia, cinética de formação da camada e características de endurecimento da camada nitretada $[5,6]$.

A principal vantagem do processo de nitretação sob plasma é a possibilidade de utilizar temperaturas de processo tão baixas quanto $350^{\circ} \mathrm{C}$ em uma cinética aceitável para processos industriais. Os mecanismos de endurecimento envolvidos na nitretação sob plasma em alta temperatura para o aço AISI 420 estão bem estabelecidos na literatura [7-I I]. No entanto, a possibilidade de usar baixas temperaturas ainda exige intensa pesquisa, a fim de descrever um modelo para o mecanismo pelo qual a microestrutura da superfície e suas propriedades são modificadas. As principais vantagens associadas ao tratamento de baixa temperatura são: (i) menor influência sobre as propriedades de corrosão, (ii) menor efeito sobre a dureza do núcleo, (iii) baixa distorção e (iv) melhor acabamento superficial após o processo.

Este artigo descreve as características da camada nitretada sob plasma do aço inoxidável martensítico AISI 420, temperado e revenido para a dureza utilizada em moldes de injeção de polímeros. Os resultados apresentados neste artigo referem-se à nitretação sob plasma em alta temperatura $\left(\mathrm{HTPN}-550^{\circ} \mathrm{C}\right)$ e em baixa temperatura (LTPN-380 $\mathrm{C}$ ). Os resultados obtidos permitem discutir com profundidade os mecanismos envolvidos na formação da camada nitretada nas duas condições diferentes de temperatura sob a abordagem termodinâmica e cinética.

\section{MATERIAIS E MÉTODOS}

Neste estudo foi utilizado um aço inoxidável martensítico AISI 420 recebido na forma de barra chata com largura de I 5,0 mm e espessura de 4,0 mm. O material foi temperado a partir de uma temperatura de austenitização de $1020^{\circ} \mathrm{Ce}$ revenido duas vezes a $510^{\circ} \mathrm{C}$, obtendo-se dureza de $50 \mathrm{HRC}$, aproximadamente $5 \mathrm{I} 2 \mathrm{HV}$. A composição química do aço é mostrada na Tabela I. Na preparação das amostras para nitretação uma das faces foi polida com acabamento final obtido com pasta de diamante de granulometria I $\mu \mathrm{m}$.

A nitretação sob plasma foi realizada em um reator com fonte DC-pulsada. A remoção do filme passivo de $\mathrm{Cr}_{2} \mathrm{O}_{3}$ foi realizada no reator por bombardeamento de plasma de hidrogênio antes da nitretação na temperatura de $380^{\circ} \mathrm{C}$ por I,5 horas. Para a nitretação foram estudadas duas condições diferentes, a primeira em temperatura elevada (HTPN), realizada a $550^{\circ} \mathrm{C}$ por 12 horas, e a segunda a baixa temperatura
(LTPN), realizada a $380^{\circ} \mathrm{C}$ por 20 horas. A mistura gasosa da atmosfera nitretante foi fixa em $75 \% \mathrm{~N}_{2}: 25 \% \mathrm{H}_{2}$ para as duas temperaturas estudadas. A temperatura foi controlada por dois termopares embutidos nas amostras. $O$ resfriamento após nitretação foi efetuado com as amostras no interior da câmara sob vácuo até temperatura ambiente.

As microestruturas foram observadas por microscopia óptica (MO) após ataque com reagente de Villela. As amostras foram imersas no reagente químico por aproximadamente I 5 segundos. A identificação das fases presentes em cada condição de tratamento superficial foi realizada por técnica de Difração de Raios-X (DRX) em um Difratômetro Shimadzu XRD-7000, em simetria de Bragg-Brentano, operando com radiação $\mathrm{Cu}-\mathrm{K} \alpha, \lambda=1,5406 \AA$. Os difratogramas foram obtidos usando velocidade de varredura angular $1 \% \mathrm{~min}$, com passo de $0,02^{\circ}$, e ângulo de varredura $(2 \theta)$ de 20 a $120^{\circ}$. Medidas de microdureza Vickers foram realizadas em um aparelho Shimadzu Modelo HMV2 com carga de $250 \mathrm{mN}$.

\section{RESULTADOS E DISCUSSÃO}

A Figura I mostra a microestrutura nas duas condições de nitretação. $\mathrm{Na}$ condição nitretada a $380^{\circ} \mathrm{C}$ (LTPN), a zona de difusão praticamente não é revelada pelo reagente metalográfico, observa-se apenas um escurecimento tênue delimitado pela linha tracejada. Por outro lado, após a nitretação a $550^{\circ} \mathrm{C}$ (HTPN) observa-se a camada nitretada fortemente atacada e a zona de difusão claramente marcada. O crescimento da camada nitretada a alta temperatura é bem discutido na literatura [7-I I] e a morfologia da zona de difusão após HTPN é típica dos aços inoxidáveis martensíticos nitretados sob condições semelhantes, apresentando zona de difusão homogeneamente escurecida com interface plana com relação ao substrato não nitretado. Esta diferença na suscetibilidade ao ataque metalográfico é uma forte evidência de que a LTPN preserva a resistência à corrosão e que esta é severamente prejudicada após a HTPN [12]. Como um resultado da diferença de temperatura do processo a espessura da camada para a LTPN foi de $23,7 \pm 2,6 \mu \mathrm{m}$ e para a HTPN de 63,2 $\pm 1,4 \mu \mathrm{m}$, como esperado já que o coeficiente de difusão do nitrogênio aumenta com o aumento da temperatura [9].

A Figura 2 apresenta o espectro de DRX para o substrato de aço AISI 420, após têmpera e revenimento, sem nitretação. Verifica-se a identificação de cinco picos com interferência construtiva para a martensita revenida ( $\left.\alpha^{\prime}\right)$. As distâncias interplanares foram calculadas para cada pico obtido no espectro de difração, utilizando a Lei de Bragg, o parâmetro do reticulado, assumido como cúbico de corpo

Tabela I. Composição química do aço AISI 420 (\% em massa)

\begin{tabular}{ccccccc}
\hline $\mathbf{C}$ & $\mathbf{S i}$ & $\mathbf{M n}$ & $\mathbf{C r}$ & $\mathbf{N i}$ & $\mathbf{P}$ & $\mathbf{S}$ \\
\hline 0,30 & 0,46 & 0,45 & 13,10 & 0,20 & 0,017 & 0,003 \\
\hline
\end{tabular}



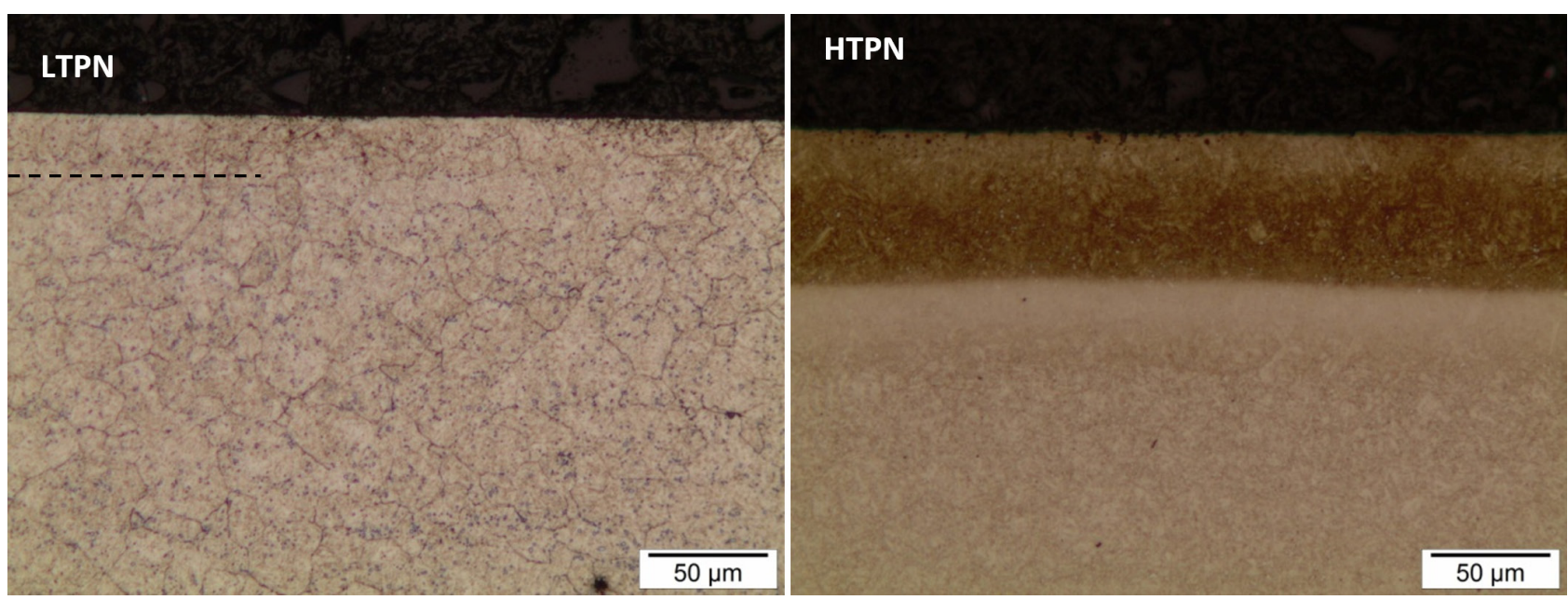

Figura I. Microestruturas transversais das superfícies após a nitretação sob plasma a baixa e a alta temperatura.

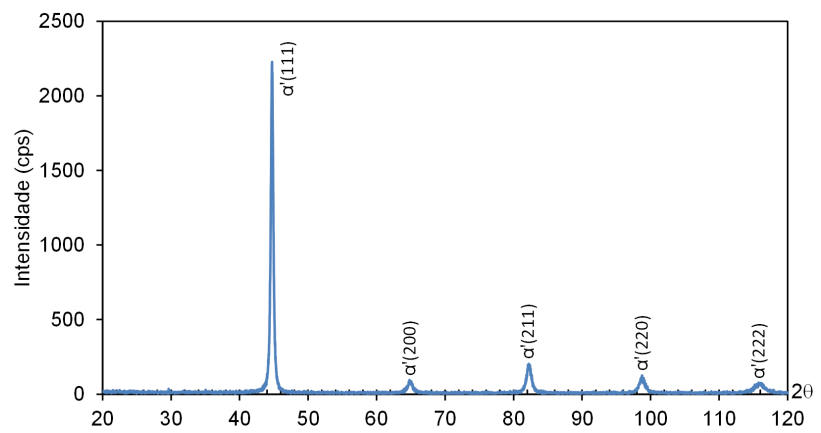

Figura 2. Espectro de DRX do aço AISI 410 no estado temperado e revenido.

de centrado, foi calculado utilizando a metodologia proposta por Nelson e Riley [13]. O valor médio do parâmetro do reticulado obtido para a martensita revenida do substrato foi de $0,287 \mathrm{~nm}$, que é idêntico ao relatado para o aço inoxidável martensítico tipo 410 de $0,287 \mathrm{~nm}$ [14].

O espectro de DRX após a nitretação sob plasma de alta temperatura, Figura 3 a, mostra os picos originais da martensita revenida não nitretada e picos indexados para o nitreto de ferro $\gamma^{\prime}-\mathrm{Fe}_{4} \mathrm{~N}$ e nitretos $\mathrm{Cr}_{2} \mathrm{~N}$ e $\mathrm{CrN}$, como esperado [I I]. No entanto, após a LTPN, Figura 3b, o espectro de DRX é completamente diferente daquele obtido para a HTPN. Mudanças microestruturais importantes ocorrem como resultado da baixa difusividade do cromo: apenas a precipitação dos nitretos de ferro é verificada pela presença dos picos de $\varepsilon-\mathrm{Fe}_{3} \mathrm{Ne} \gamma^{\prime}-\mathrm{Fe}_{4} \mathrm{~N}$ com nenhuma precipitação de nitretos de cromo. Picos de baixa intensidade de reflexão para ferrita não são observados, somente um pico de alta intensidade na posição de $43,18^{\circ}$ indexado como correspondente ao mais próximo de ferrita (II0). Comparado com a condição não nitretada é verificado que o pico de reflexão ( 1 I0) depois da LTPN ocorre para um valor de $2 \theta$ inferior ao $44,74^{\circ}$ original, claramente observado quando comparado com a linha tracejada marcando a posição original $\alpha^{\prime}(\mathrm{I} \mid \mathrm{l})$. O parâmetro de rede possível de ser calculado com a distância interplanar a ele associada é de $0,296 \mathrm{~nm}$, superior ao calculado para a condição não nitretada $0,287 \mathrm{~nm}$. Além disso, comparando os picos ( 110 ) antes e após a nitretação é claro o alargamento deste pico após nitretação a $380^{\circ} \mathrm{C}$.

Estas características observadas no DRX após a LTPN, o deslocamento de $2 \theta$ para ângulos menores, com o aumento do parâmetro de rede, associado a um aumento da largura à meia altura (FWHM) são evidências que permitem aos autores considerarem a formação de "martensita revenida expandida pelo nitrogênio" ou " $\alpha$ ', , semelhante ao proposto para a formação de austenita expandida em nitretação, cementação ou nitrocarburação de aço inoxidável austenítico AISI 316L após a LTPN [15-18], como consequência da supersaturação nos elementos intersticiais, nitrogênio e/ou carbono. Apesar da formação de austenita expandida ser amplamente discutida, a discussão dos mecanismos para os aços inoxidáveis martensíticos não está definido na literatura. Alguns estudos existentes referem-se à formação de "ferrita expandida" ou "martensita expandida" [19-22]. Quando a nitretação é realizada a uma temperatura tão baixa quanto $380^{\circ} \mathrm{C}$ a cinética de precipitação de nitretos é baixa e a precipitação dos nitretos de cromo é inibida. No entanto, na nitretação a $550^{\circ} \mathrm{C}$ o coeficiente de difusão de cromo é suficientemente alto para permitir a difusão deste elemento substitucional para a precipitação de nitretos de cromo mais complexos [10]. É importante salientar que na HTPN a intensa precipitação de nitretos consome $o$ nitrogênio disponível na zona de difusão, inibindo a supersaturação e, portanto, a formação de "martensita revenida expandida". Ainda, a martensita revenida sofre um alívio de tensões, por consequência do tempo de permanência na temperatura de nitretação, o que promove um deslocamento dos picos de difração correspondentes para a direita, com relação ao material não nitretado. Apesar do super-revenimento [I I], 
- parâmetro de reticulado calculado para a martensita revenida, utilizando o tratamento de Nelson e Riley [13], após a nitretação sob plasma a alta temperatura permanece sendo de $0,287 \mathrm{~nm}$, ou seja, o deslocamento não é suficiente para alterar o valor calculado.

A nitretação do aço inoxidável martensítico em diferentes temperaturas deve ser discutida considerando um conjunto de variáveis que interagem e modificam a microestrutura da camada nitretada e o mecanismo de endurecimento. Por isso, é importante considerar o papel: (i) da interação termodinâmica entre o nitrogênio e o elemento de liga de substitucional do sistema Fe-Cr-N, (ii) o teor de cromo no aço e (iii) o coeficiente de difusão do cromo nas diferentes temperaturas de nitretação, 380 e $550^{\circ} \mathrm{C}$. Considerando a interação entre o elemento substitucional $(X)$ formador de nitreto e o nitrogênio, os trabalhos [5,6] mostram que na presença do elemento substitucional a cinética de crescimento da camada nitretada não é proporcional apenas ao coeficiente de difusão do nitrogênio e ao tempo, mas deve ser considerada a interação X-N. Esta interação promove um constante aprisionamento do $\mathrm{N}$ pelos átomos do elemento substitucional até que a precipitação do nitreto se efetue. Quando a interação X-N é de caráter forte a interface de nitretação cresce por um mecanismo do tipo de aprisionamento/liberação do nitrogênio (trap-no trap) e assim assume uma morfologia de interface de crescimento plana com o substrato. Nesta linha Ti e V são elementos que têm forte interação com $\mathrm{N}$ para qualquer concentração na liga, enquanto a característica de interação entre cromo e nitrogênio depende do teor deste elemento na liga. Para teores de cromo acima de $9 \%$ em massa a interação $\mathrm{Cr}-\mathrm{N}$
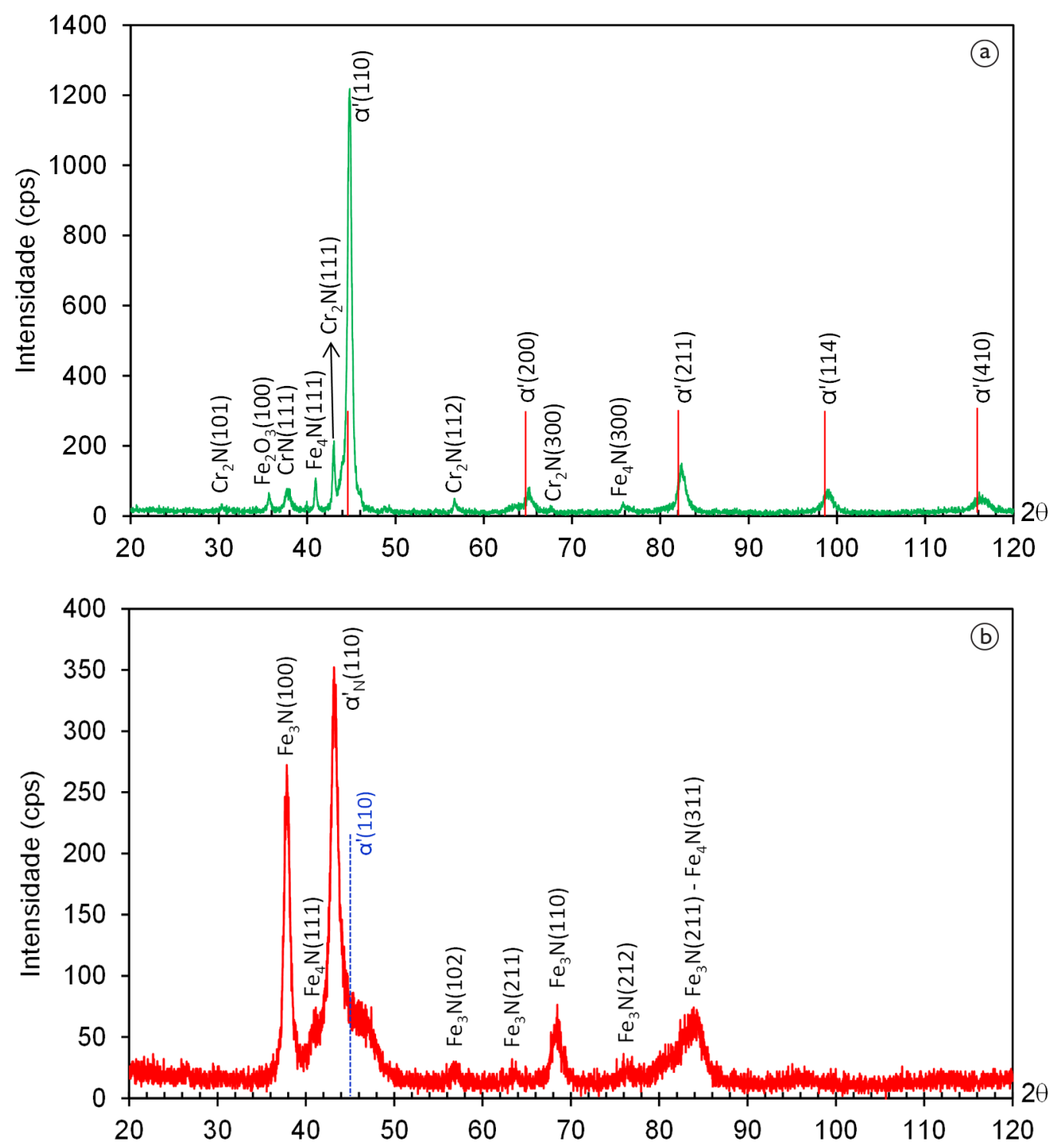

Figura 3. Espectros de DRX do aço AISI 4 I 0 no estado (a) nitretado sob plasma a alta temperatura e (b) nitretado sob plasma a baixa temperatura. 
é de caráter forte e para teores menores a interação é intermediária.

Em trabalho recente [23] Jung mostra a influência da interação entre o nitrogênio e o elemento substitucional formador de nitreto $(X)$, no perfil de composição transversal de nitrogênio através da camada nitretada. Este perfil muda substancialmente em função do tipo de interação X-N. Quando a interação $X-N$ é do tipo forte o perfil de composição do nitrogênio é do tipo "plano", com teor máximo de nitrogênio constante ao longo de toda a profundidade da camada nitretada, seguido de uma queda acentuada após interface de nitretação em direção do núcleo. Quando a interação X-N é do tipo intermediário o perfil de composição é "difuso" com uma diminuição gradual no teor de nitrogênio através da camada nitretada em direção ao núcleo. A Figura 4 é apresentada para mostrar estes diferentes comportamentos.

Curvas como as apresentadas na Figura 4 deveriam ser obtidas para aços com teores de cromo diferentes. Entretanto, no presente trabalho verifica-se que o mecanismo de crescimento da camada nitretada depende não só das características de interação entre o par de $\mathrm{Cr}-\mathrm{N}$, mas da influência da temperatura do processo de nitretação, evidenciado pelas características microestruturais e pelos perfis de endurecimento transversais a camada nitretada.

Considerando que as curvas de endurecimento transversal através da camada nitretada devem seguir o perfil composicional de nitrogênio, verifica-se neste trabalho que o mecanismo de nitretação pode ser modificado pela temperatura de nitretação, considerando que o teor de cromo no aço em estudo é fixo em 13,5\% em massa. Verifica-se pela Figura 5 que curvas de endurecimento transversal têm sua característica de forma modificada em função da temperatura de nitretação.

$\mathrm{Na}$ nitretação a alta temperatura $\left(\mathrm{HTPN}-550^{\circ} \mathrm{C}\right)$ o perfil de endurecimento é do tipo plano e coincide com uma interação $\mathrm{Cr}-\mathrm{N}$ do tipo forte. $\mathrm{O}$ presente resultado coincide com resultados anteriores da literatura apresentados para a nitretação sob plasma do aço inoxidável martensítico AISI 420 (Fe-0,4\%C-I3,5\%Cr), onde as curvas de endurecimento transversal tem uma característica endurecimento máximo plano por toda a espessura da camada nitretada com queda acentuada em direção ao núcleo após a interface de nitretação, mostrando que a interação entre o nitrogênio e o cromo tem características definidas como fortes quando o processo de nitretação é conduzido a temperaturas acima de $480^{\circ} \mathrm{C}$, que permitem a formação de nitretos de cromo na camada, como observado pelo difratograma da Figura 3a [7-I I].

$\mathrm{Na}$ nitretação sob plasma a baixa temperatura $\left(\mathrm{LTPN}-380^{\circ} \mathrm{C}\right.$ ) o perfil transversal de dureza se modifica para o tipo difuso, visto que não existe a possibilidade de difusão do cromo por restrições cinéticas, o que impede que o fator termodinâmico da interação $\mathrm{Cr}-\mathrm{N}$ possa atuar e desta forma e o crescimento da camada tem comportamento com interação do tipo intermediário. Enquanto o mecanismo de

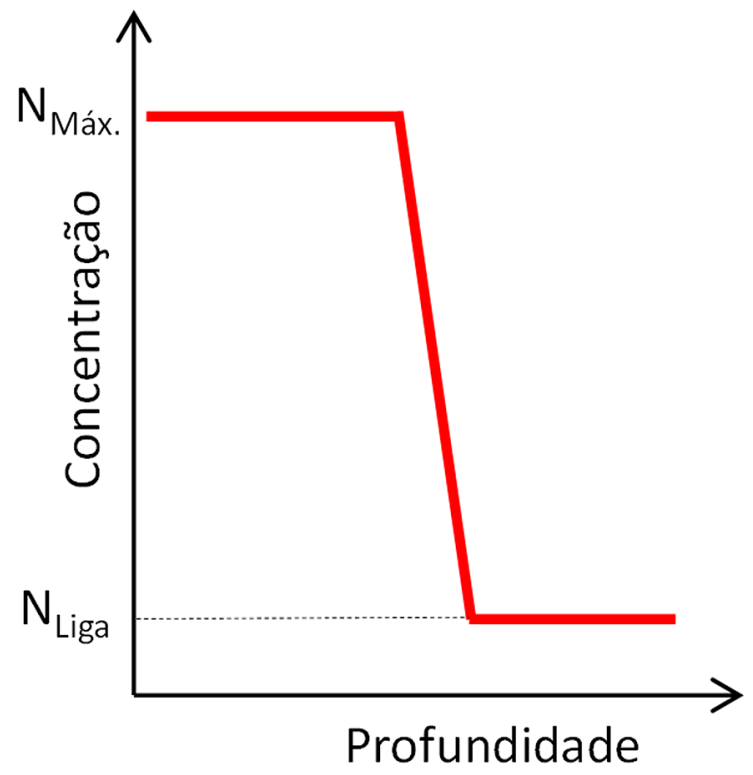

Interação Forte

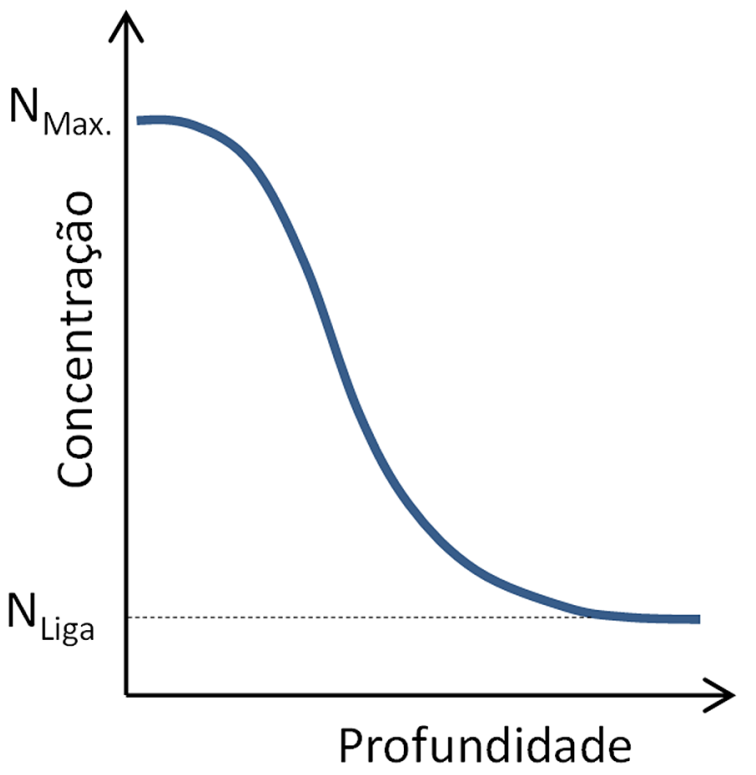

Interação Intermediária

Figura 4. Perfil composicional do nitrogênio para a nitretação de ligas contendo elementos formadores de nitretos com diferentes características de interação X-N. 


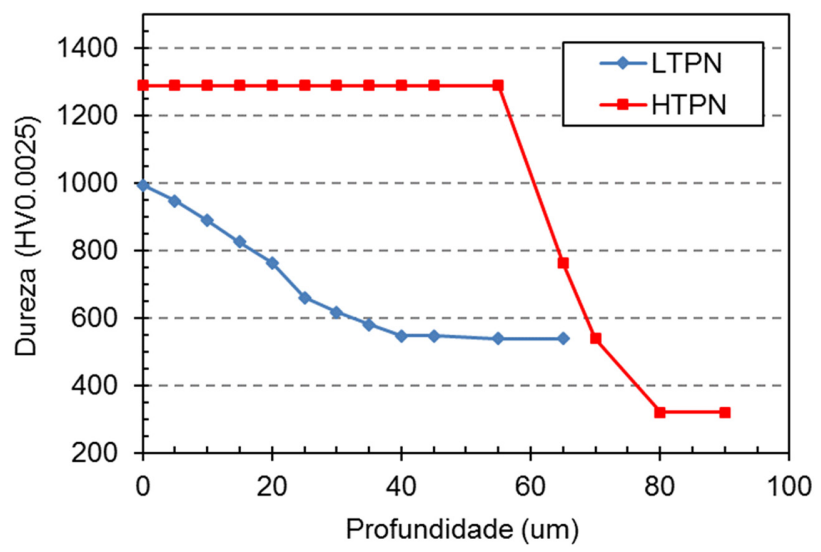

Figura 5. Perfis de endurecimento transversal para a nitretação sob plasma a baixa e a alta temperatura.

endurecimento na HTPN é a precipitação fina e homogênea de nitretos de cromo atingindo um máximo de próximo de $1300 \mathrm{HV} 0,025$, na LTPN a menor dureza máxima, de $993 \mathrm{HV} 0,025$, tem como mecanismo de endurecimento a precipitação de nitretos de ferro e a supersaturação em $\mathrm{N}$ da martensita revenida expandida, e estas fases podem ser identificadas no difratogramas da Figura 3b. Como a martensita revenida expandida está supersaturada em N, apresenta endurecimento por solução sólida, não sendo possível na LTPN isolar a contribuição dos mecanismos de endurecimento. Um resultado importante para o processo de LTPN é a manutenção da dureza do substrato nos níveis elevados obtidos após a têmpera e revenimento, após a nitretação, $537 \mathrm{HV} 0,025$. Verifica-se que após a nitretação a alta temperatura a dureza do substrato diminui para $320 \mathrm{HV} 0,025$. Essa diminuição da dureza do substrato é consequência do super-revenimento que ocorre pela exposição à temperatura $\mathrm{e}$ tempo de nitretação em temperatura elevada [ I I]. Com isso, a nitretação de componentes industriais pode ser realizada de forma segura em temperaturas próximas de $400^{\circ} \mathrm{C}$ garantindo a preservação das propriedades mecânicas do núcleo do componente.

Para a condição de HTPN utilizada a difusão de nitrogênio, juntamente com a de cromo, permite a precipitação de nitretos de cromo, $\mathrm{CrN}$ e $\mathrm{Cr}_{2} \mathrm{~N}$, levando a formação da interface de crescimento plana. A menor energia livre para a formação de $\mathrm{Cr}_{2} \mathrm{~N}$ em comparação com o $\mathrm{CrN}$ [24] explica a maior incidência de picos de $\mathrm{Cr}_{2} \mathrm{~N}$ no espectro de DRX da Figura 3a. A microestrutura observada para a HTPN (Figura I) é uma evidência direta de que o mecanismo proposto por Jack para a interação forte entre $X-N$ é válido para teores elevados de cromo em alta temperatura, ou seja, camada homogênea com interface plana junto ao substrato. $\mathrm{Na}$ nitretação a baixa temperatura, quando a difusividade do cromo é desprezível, a cinética de crescimento da camada nitretada segue o modelo padrão aplicado para os aços carbono e de baixa liga, proporcional apenas à difusão do nitrogênio e ao tempo, gerando uma interface de crescimento do tipo difusa, não se observando nítida transição entre camada e substrato, e assim a necessidade cinética se impõe sobre a necessidade termodinâmica.

\section{CONCLUSÕES}

- O uso da nitretação sob plasma a alta temperatura, HTPN $-550^{\circ} \mathrm{C}$, promove a intensa precipitação e nitretos de ferro $\gamma^{\prime}-\mathrm{Fe}_{4} \mathrm{~N}$ e de cromo $\mathrm{Cr}_{2} \mathrm{~N}$ e $\mathrm{CrN}$.

- O ciclo de nitretação sob plasma a baixa temperatura, LTPN $-380^{\circ} \mathrm{C}$, promove a formação de uma camada nitretada composta de "martensita revenida expandida por nitrogênio" $\left(\alpha_{N}^{\prime}\right)$, com parâmetro de rede $0,296 \mathrm{~nm}$, superior ao do substrato que é de $0,292 \mathrm{~nm}$. Além disso, ocorre a precipitação de nitretos de ferro tipo $\varepsilon-\mathrm{Fe}_{3} \mathrm{~N}$ e $\gamma^{\prime}-\mathrm{Fe}_{4} \mathrm{~N}$, e não há precipitação de nitretos de cromo. Nesta temperatura o mecanismo de nitretação é controlado pela cinética de difusão do elemento substitucional, cromo.

- Na HTPN o potencial de endurecimento é máximo atingindo a dureza de $1300 \mathrm{HV}$ devido à intensa precipitação de nitretos de ferro e cromo na zona de difusão.

- Na LTPN o potencial máximo de endurecimento é inferior ao da HTPN, atingindo uma dureza máxima próxima de $990 \mathrm{HV}$. O endurecimento é causado pela formação de "martensita revenida expandida pelo nitrogênio" $\left(\alpha_{N}^{\prime}\right)$ e pela precipitação de nitretos de ferro.

- Os perfis de endurecimento transversal, tipo plano ou difuso, são consequência dos mecanismos de nitretação operantes. Na HTPN o perfil de dureza é do tipo plano e na LTPN do tipo difuso. Isto ocorre provavelmente porque quando a nitretação é realizada na temperatura de $550^{\circ} \mathrm{C}$ a formação e crescimento da camada nitretada é controlada pelo potencial termodinâmico de formação de nitretos de cromo e a possibilidade de formação destes pela possibilidade de difusão tanto de $\mathrm{N}$ quanto de $\mathrm{Cr}$ na temperatura do processo. Contudo, quando a nitretação é realizada a $380^{\circ} \mathrm{C}$ as restrições cinéticas de difusão de $\mathrm{Cr}$ modificam os mecanismos de crescimento da camada nitretada, e o aço se comporta como uma liga de baixo teor de cromo, ocorrendo a precipitação preferencial de nitretos de ferro e a expansão do reticulado da martensita revenida pela supersaturação em $\mathrm{N}$.

- Na nitretação HTPN as condições térmicas do processo diminuem a dureza do substrato. Na LTPN as condições térmicas do processo preservam a dureza de partida do substrato. 


\section{REFERÊNCIAS}

I Sun T, Bell T. Plasma surface engineering. Materials Science and Engineering. 1991;140:4 | 9-434. http://dx.doi. org/I0.1016/092I-5093(91)90458-Y.

2 Edenhofer B. Physical and metallurgical aspects of ion nitriding. Heat Treatment of Metals. 1974;(I)23-28.

3 Pye D. Practical nitriding and ferritic nitrocarburizing. Materials Park: ASM International; 2003.

4 Yang M. Nitriding: fundamentals, modeling and process optimization [PhD theses]. Worcester: Worcester Polytechnic Institute; 2012.

5 Jack DH. Nitriding. In: Heat Treatment'73. London; 1973. p. 39-50</conf >.

6 Lightfoot J, Jack DH. Kinetics of nitriding with and without compound layer formation. In: Heat Treatment'73. London; 1973. p. 59-65.

7 Pinedo CE, Monteiro WA. Characterization of plasma nitrided case on martensitic stainless steel by scanning electron microscopy. Acta Microscopica. 2001;1:315-316.

8 Pinedo CE, Monteiro WA. Surface hardening by plasma nitriding on high chromium alloy steel. Journal of Materials Science Letters. 200 I;20(2): 147-I49. http://dx.doi.org/I0.1023/A:I0067232255I5.

9 Pinedo CE, Monteiro WA. On the kinetics of plasma nitriding a martensitic stainless steel type AISI 420. Surface and Coatings Technology. 2004;179(2-3): I 19-123. http://dx.doi.org/I0.1016/S0257-8972(03)00853-3.

10 Pinedo CE. The use of selective plasma nitriding on piston rings for performance improvement. Materials \& Design. 2003;24(2): I3I-I35. http://dx.doi.org/I0.1016/S026I-3069(02)00I2I-8.

II Pinedo CE, Monteiro WA. Tratamento térmico e nitretação sob plasma do aço inoxidável martensítico AISI 420. Tecnologica em Metalurgia, Materiais e Mineração. 201 I;8: I-5.

12 Liang W, Bin X, Zhiwei Y, Yaqin S. The wear and corrosion properties of stainless steel nitrided by low-pressure plasma-arc source ion nitriding at low temperatures. Surface and Coatings Technology. 2000; I30(2-3):304-308. http://dx.doi.org/I0.1016/S0257-8972(00)007/3-I.

13 Nelson JB, Riley DP. An Experimental Investigation of Extrapolation Methods in the Derivation of Accurate Unit-Cell Dimensions of Crystals. Proceedings of the Physical Society. 1945;57(3): 160- I77. http://dx.doi.org/10. 1088/09595309/57/3/302.

14 The International Centre for Diffraction Data - ICDD. Card 00-054-033 I, 4 IOL: stainless steel, ferrite. Newtown Square.

15 Mingolo N, Tschiptschin AP, Pinedo CE. On the formation of expanded austenite during plasma nitriding of an AISI 3I6L austenitic stainless steel. Surface and Coatings Technology. 2006;20 I (7):42I5-42 I8. http://dx.doi. org/10.1016/j.surfcoat.2006.08.060.

16 Souza RM, lgnat M, Pinedo CE, Tschiptschin AP. Structure and properties of low temperature plasma carburized austenitic stainless steels. Surface and Coatings Technology. 2009;204(6-7): I 102-I I05. http://dx.doi.org//0. I016/j. surfcoat.2009.04.033.

17 Dong H. S-phase surface engineering of $\mathrm{Fe}-\mathrm{Cr}, \mathrm{Co}-\mathrm{Cr}$ and $\mathrm{Ni}-\mathrm{Cr}$ alloys. International Materials Reviews. 2010;55(2): I-34. http://dx.doi.org/I0.I I79/095066009XI2572530I70589.

18 Pinedo CE, Tschiptschin AP. Low temperature nitriding, nitrocarburizing and carburizing of AISI 316L austenitic stainless steel. International Heat Treatment and Surface Engineering. 20I I;5(2):73-77. http://dx.doi.org/I0.1 I79/17 495I4IIXI305I201040703.

19 Wu K, Liu GQ, Wang L, Xu BF. Research on new rapid and deep plasma nitriding techniques of AISI 420 martensitic stainless steel. Vacuum. 2010;84(6):870-875. http://dx.doi.org/10.1016/j.vacuum.2009.12.00I.

20 Kim SK, Yoo JS, Priest JM, Fewell MP. Characteristics of martensitic stainless steel nitriding a low-pressure RF plasma. Surface and Coatings Technology. 2003;163-164:380-385. http://dx.doi.org/10.1016/S02578972(02)0063I-X.

2I Xi Y-T, Liu D-X, Dong H. Improvement of mechanical properties of martensitic stainless steel by plasma nitriding at low temperature. Acta Metallurgica Sinica. Engl. Letter. 2008;21:21-29.

$22 \mathrm{Xi}$ Y, Liu D, Han D. Improvement of corrosion and wear resistances of AISI 420 martensitic stainless steel using plasma nitriding at low temperature. Surface and Coatings Technology. 2008;202(I2):2577-2583. http://dx.doi. org/10.1016/j.surfcoat.2007.09.036. 
23 Jung KS. Nitriding of iron-based ternary alloys: Fe-Cr-Ti and Fe-Cr-Al [PhD theses]. Stuttgart: Max-Planck-Institut für Metallforschung; 2012.

24 Henderson S. Solute interactions in nitrided iron alloys [PhD theses]. Newcastle: University of Newcastle upon Tyne; 1976.

Recebido em: 3 Dez. 2014

Aceito em: 15 Jun. 2015 